\title{
Flexible Microwave Antenna Applicator for Chemothermotherapy of the Breast
}

\author{
Erdem Topsakal ${ }^{1}$, Mustafa Asili ${ }^{1}$, Pu Chen $^{2}$, Utkan Demirci $^{2,3}$, and Nicholas Younan ${ }^{1}$
}

\begin{abstract}
In this study, a flexible microwave antenna applicator is presented for mild microwave hyperthermia. The antennas used in this study are designed for high dielectric medium -like skin and tested using tissue mimicking gels that mimic the dielectrical properties of the human breast. After the initial antenna design the applicator is fabricated embvedding the antennas in PDMS. Finaly, we have tested the applicator using masimu of $5 \mathrm{~W}$ input power. The experiments sugges that the proposed applicator provides a considerable heating up to $4 \mathrm{~cm}$ depth with $5 \mathrm{~W}$ at $450 \mathrm{MHz}$.
\end{abstract}

Index Terms-Thermotherapy, microwave hyperthermia

\section{INTRODUCTION}

$\mathrm{T}$ HE NUMBER of women suffering from breast cancer is escalating day by day. It is one of the most common causes of death among women [1]. Conventional treatments of cancers are chemotherapy, radiotherapy and surgery. Hyperthermia, (thermotheray) is also used as an adjunctive therapy to raise the temperature of cancerous cells. This form of therapy, paired with conventional therapies provides more success during cancer treatment due to the exposure of electromagnetic energy as heat to the cells thus reducing the resistance of the cancer treatment for the affected tissue [2][6]. In tumors, vascularisation and blood flow is lower than that of reqular tissues, so it makes the cancer tissue more heat sensitive [4]. This property of tumors makes classical treatment more efficient when it is combined with microwave hyperthermia. Hyperthermia causes an increase in perfusion which increases the drug delivery and the radiotherapy efficiacy [6]. Combining radiotherapy or chemotherapy and hyperthermia treatments provides higher survial and remission rates, and it increases complete response of radiotherapy from41 to 59 percent [7].

In order to make it more feasible and applicable, low power and suitable applicators should be used. The goal of this method is to raise the temperature of the whole organ or tissue a few degrees, and then allow conventional therapies to

\footnotetext{
${ }^{1}$ Department of Electrical and Computer Engineering, Mississippi State University, Mississippi State, MS 39762, USA (email:ma878@msstate.edu; eec77@msstate.edu; azh1@msstate.edu; aep152@msstate.edu; rwh138@msstate.edu; topsakal@ece.msstate.edu).

${ }^{2}$ Bio-Acoustic MEMS in Medicine (BAMM) Lab, Department of Radiology, School of Medicine, Canary Center for Early Cancer Detection, Stanford University, Palo Alto, CA 94304

${ }^{3}$ Department of Medicine, Brigham \& Women's Hospital, Harvard Medical School, MA,02139, USA.
}

destroy the cancerous tissue without damaging the healthy cells. The temperature interval for microwave hyperthermia is from $41^{\circ} \mathrm{C}$ to $45^{\circ} \mathrm{C}$ for cancer treatment [5]. In addition to its ease of use, this method is inexpensive, it requires low power, and therapy time is limited to 10 minutes to implement. For this purpose, we have fabricated the antennas onto a flexible

material, so it is easy to give a form to antenna array on the bra, and the details of the material will be explained in the following section.

\section{ANTENNA FABRICATION}

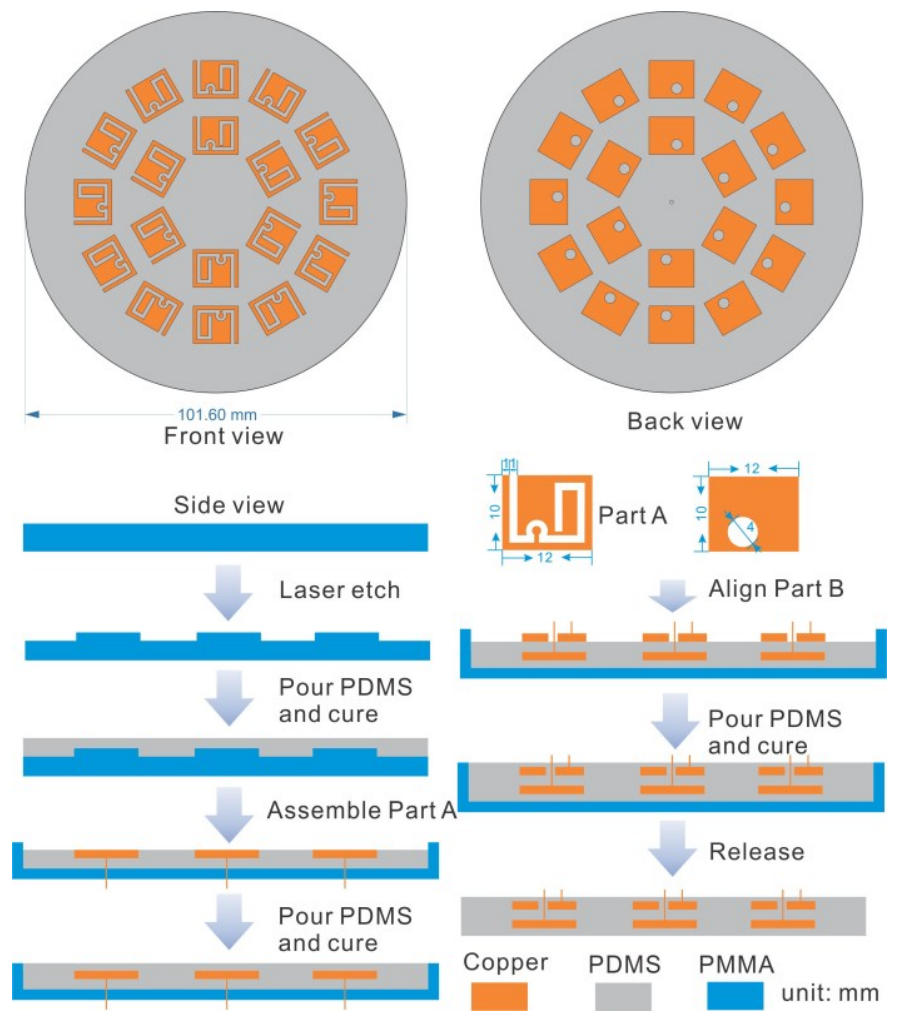

Fig. 1. Design and fabrication of flexible antenna applicator.

Design and fabrication of flexible microwave antenna applicator are demonstrated in Fig. 1. Briefly, 18 small antennas were arranged along two concentric circles in a radial manner and integrated in circle-shaped flexbile PDMS sheet. Each small antenna was made of two parts of machined copper foils $(50 \mu \mathrm{m}, 9053 \mathrm{~K} 312$, McMaster-Carr), on which copper wires were soldered as the feedlines. A $1.5-\mathrm{mm}$ thick 
PDMS sheet with alignment pattern was fabricated using a PMMA mold that was made by laser etching. Bottom parts of small antennas were assembled on the PDMS sheet according to alignment pattern. The bottom parts were further sealed into the PDMS sheet by coating with fresh PDMS prepolymer mixture (i.e., ratio of PDMS precusor to curing agent is 10:1) and curing at $80^{\circ} \mathrm{C}$ for 1 hour. Similarly, the top parts of the antennas were aligned on the PDMS sheet based on the bottom parts. The top parts were covered with fresh PDMS prepolymer mixture and cured at $80^{\circ} \mathrm{C}$ for 1 hour. The flexible microwave antenna applicator was obtained by being released from the PMMA container,

\section{IN VITRO MEASUREMENTS}

The antenna designed in [3] is used to create the filexible antenna applicator shown in Fig. 2. It was designed on FR4 substrate. For this application, it is fabricated on a flexible material and we tested this antenna in air and on human breast-mimicking gels (Fig. 3) that contains skin, fat and fibroglandular layers. As it is seen (Fig. 4), it resonates at $450 \mathrm{MHz}$ on breast tissue well (below $-10 \mathrm{~dB}$ ) but does not in air. Fig. 5 shows the test bench including signal generator, amplifier, temperature sensors and the computer used to observe the temperature changes.

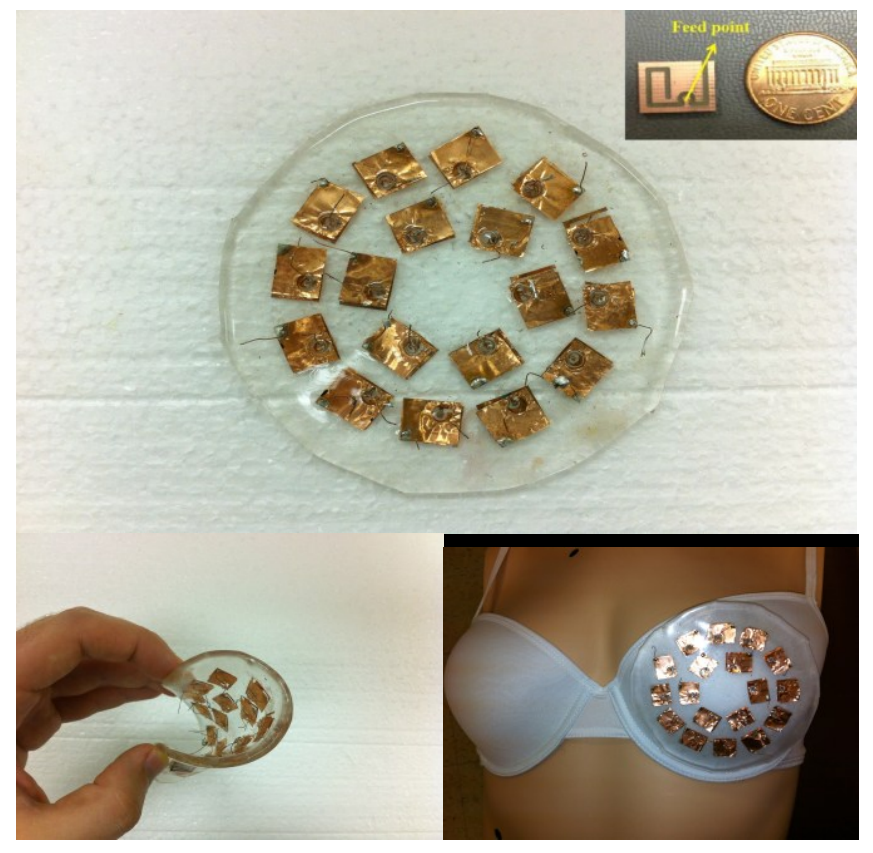

Fig. 2. Microwave antenna applicator printed on a flexible material.

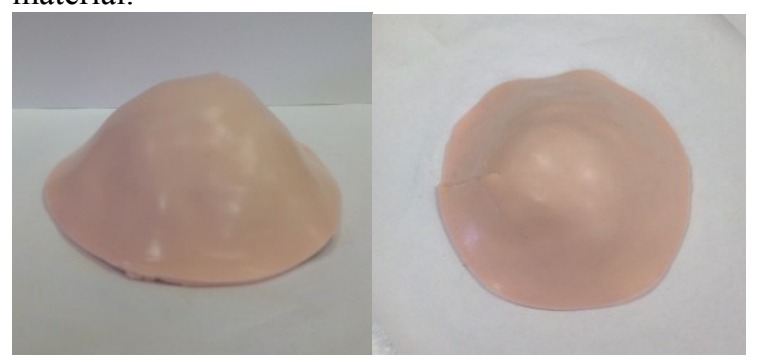

Fig. 3. Side and top view of the gel.

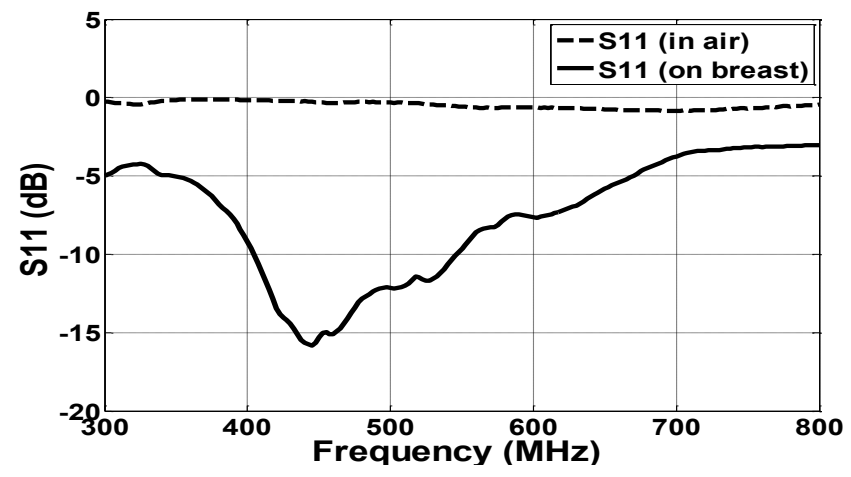

Fig. 4. Return loss of the microwave antenna.

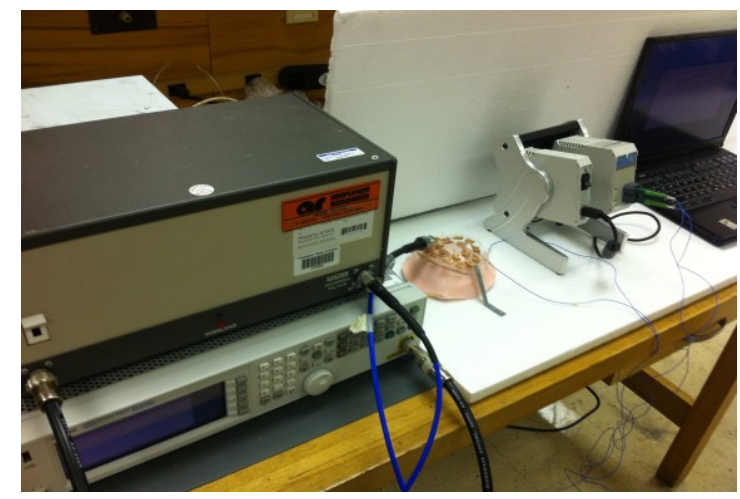

Fig. 5. Experimental setup.

The microwave antenna applicator is attached on the breastmimicking gels, and the power is pumped through the antenna. Firstly, we measured the temperature rise at the depth of $1 \mathrm{~cm}$ with $1 \mathrm{~W}$ power at $450 \mathrm{Mhz}$. Then, gradually increased power up to $5 \mathrm{~W}$ and applied at $1 \mathrm{~cm}$ depth. Thereafter, we increased the depth and repeated the measurements at $2.5 \mathrm{~cm}$ and $4 \mathrm{~cm}$ depths for all power levels again. The results of the measurements in the depth of $1 \mathrm{~cm}$ is shown in Fig. 6. We observed for $3{ }^{\circ} \mathrm{C}$ increment the temperature at the depth of $1 \mathrm{~cm}$ without time limit. However, at $2.5 \mathrm{~cm}$ and $4 \mathrm{~cm}$ depths, we limited the time to 10 minutes and observed the increments in temperature at the end of this period. All the results of other power levels' measurements are shown in Fig. 7 and Fig. 8, respectively. Table 1 also indicates the temperature increments, duration of applied power and duration of cooling for each levels.

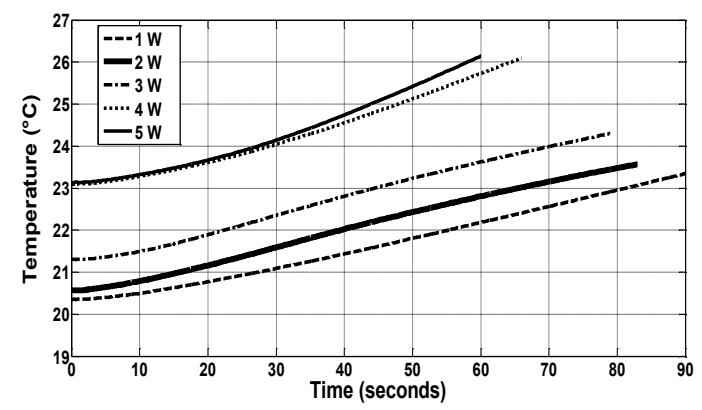

Fig. 6. Temperature increment in the depth of $1 \mathrm{~cm}$ at $450 \mathrm{MHz}$ with $1 \mathrm{~W}, 2 \mathrm{~W}, 3 \mathrm{~W}, 4 \mathrm{~W}$, and $5 \mathrm{~W}$. 


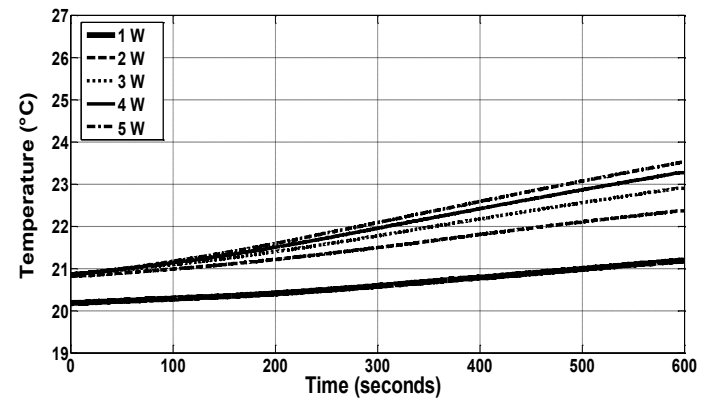

Fig. 7. Temperature increment in the depth of $2.5 \mathrm{~cm}$ at $450 \mathrm{MHz}$ with $1 \mathrm{~W}, 2 \mathrm{~W}, 3 \mathrm{~W}, 4 \mathrm{~W}$, and $5 \mathrm{~W}$.

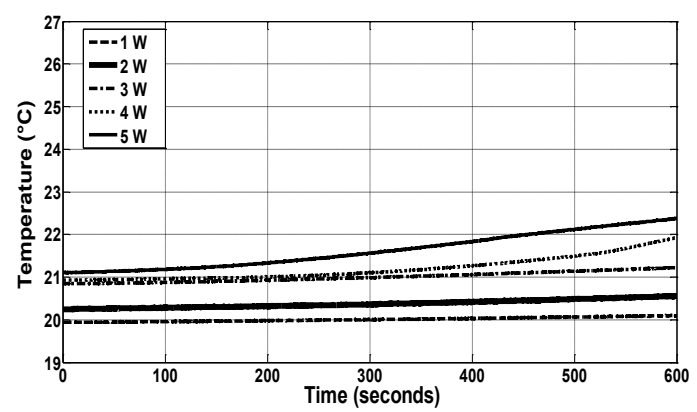

Fig. 8. Temperature increment in the depth of $4 \mathrm{~cm}$ at $450 \mathrm{MHz}$ with $1 \mathrm{~W}, 2 \mathrm{~W}, 3 \mathrm{~W}, 4 \mathrm{~W}$, and $5 \mathrm{~W}$.

Fig. 9 shows temperature rises on the surface of the gel for each power level in 10 minutes.

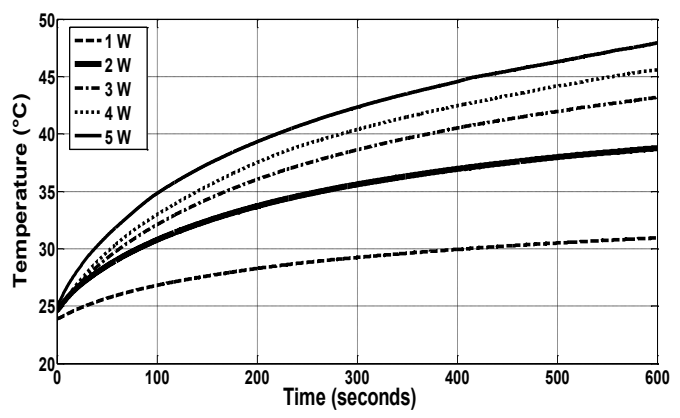

Fig. 9. Temperature changes on the surface of the gel (seconds vs. Celsius degree)

\section{TABLE I}

List of DURATION OF APPLICATION AND COOLING

\begin{tabular}{|l|l|l|l|}
\hline & \multicolumn{1}{|c|}{$\mathbf{1} \mathbf{c m}$} & \multicolumn{1}{c|}{$\mathbf{2 . 5} \mathbf{~ c m}$} & \multicolumn{1}{c|}{$\mathbf{4} \mathbf{~ c m}$} \\
\hline $\mathbf{1 W}$ & $90 \mathrm{sec} / 19 \mathrm{~min} / 3^{\circ} \mathrm{C}$ & $10 \mathrm{~min} / 30 \mathrm{~min} / 1^{\circ} \mathrm{C}$ & $10 \mathrm{~min} / 25 \mathrm{~min} / 0.15^{\circ} \mathrm{C}$ \\
\hline $\mathbf{2 W}$ & $83 \mathrm{sec} / 19 \mathrm{~min} / 3^{\circ} \mathrm{C}$ & $10 \mathrm{~min} / 34 \mathrm{~min} / 1.55^{\circ} \mathrm{C}$ & $10 \mathrm{~min} / 32 \mathrm{~min} / 0.313^{\circ} \mathrm{C}$ \\
\hline $\mathbf{3 W}$ & $79 \mathrm{sec} / 19 \mathrm{~min} / 3^{\circ} \mathrm{C}$ & $10 \mathrm{~min} / 49 \mathrm{~min} / 2.025^{\circ} \mathrm{C}$ & $10 \mathrm{~min} / 37 \mathrm{~min} / 0.385^{\circ} \mathrm{C}$ \\
\hline $\mathbf{4 W}$ & $66 \mathrm{sec} / 19 \mathrm{~min} / 3^{\circ} \mathrm{C}$ & $10 \mathrm{~min} / 63 \mathrm{~min} / 2.4^{\circ} \mathrm{C}$ & $10 \mathrm{~min} / 48 \mathrm{~min} / 1^{\circ} \mathrm{C}$ \\
\hline $\mathbf{5 W}$ & $60 \mathrm{sec} / 19 \mathrm{~min} / 3^{\circ} \mathrm{C}$ & $10 \mathrm{~min} / 67 \mathrm{~min} / 2.644^{\circ} \mathrm{C}$ & $10 \mathrm{~min} / 60 \mathrm{~min} / 1.28^{\circ} \mathrm{C}$ \\
\hline \multicolumn{4}{|l|}{ duratin of application $/$ cooling time $/$ increment in celcius degree } \\
\hline
\end{tabular}

\section{CONCLUSION}

In this letter, we presented a flexible microwave antenna applicaor for thermotherapy. This method can provide more success when it is combined with common therapies like chemotherapy and radiotherapy. According to measurements of antenna's $\mathrm{S}_{11}$ value, tests are performed at $450 \mathrm{Mhz}$. As results have shown, more than 1 celcius degree increment can be achieved in the depth of the breast with $5 \mathrm{~W}$ at $450 \mathrm{Mhz}$.

\section{References}

[1] U.S. Cancer Statistics Working Group. United States Cancer Statistics: 1999-2009 Incidence and Mortality Web-based Report. Atlanta: U.S. Department of Health and Human Services, Centers for Disease Control and Prevention and National Cancer Institute; 2013. Available: www.cdc.gov/uscs.

[2] O. Rychlik' and J. Vrba, "Planar spiral applicator for local microwave thermotherapy," in $14^{\text {th }}$ Conf. Microw. Tech.(COMITE '08), Apr., pp. 13,2008 .

[3] M. Asili, R. Green, S. Seran, and E. Topsakal, "A small implantable antenna for medradio and ISM bands," IEEE Antennas Wireless Propag. Lett., vol. 11, pp. 1683-1685, 2012.

[4] A. Y. Cheung and J. Al-Atrash, "Microwave hyperthermia for cancer therapy," IEEE Proceedings, vol. 134, pp. 493-522, 1987.

[5] B. Vrbova and J. Vrba, "Microwave thermotherapy in cancer treatment: evaluation of homogeneity of SAR distribution," Progress In Electromagnetics Research, vol. 129, pp. 181-195, 2012.

[6] P. Wust et al., "Hyperthermia in cancer treatment: hyperthermia in combined treatment of cancer," The Lancet Oncology, vol. 3, pp. 487497, 2002.

[7] M. H. Falk and R. D. Issels, "Hyperthermia in oncology," Int. J. Hyperthermia, vol. 17, pp. 1-18, 2001. 